\title{
Throat Carriage of Staphylococcus aureus
}

\author{
Ruchi Kotpal $^{\text {** }}$, Krishna Prakash ${ }^{2}$, Preena Bhalla ${ }^{2}$, Richa Dewan ${ }^{2}$ and Ravinder Kaur ${ }^{2}$ \\ ${ }^{1}$ Department of Microbiology, Mulayam Singh Yadav Medical College, UP, India \\ ${ }^{2}$ Department of Microbiology, Maulana Azad Medical College, Delhi, India \\ *Corresponding author
}

\section{A B S T R A C T}

\begin{tabular}{l} 
K e y w o r d s \\
Throat carriage, \\
Human \\
Immunodeficiency \\
$\begin{array}{l}\text { Virus, } \\
\text { Staphylococcus } \\
\text { aureus, Nasal } \\
\text { carriage }\end{array}$ \\
Article Info \\
\hline $\begin{array}{l}\text { Accepted: } \\
\text { 07 October } 2020 \\
\text { Available Online: } \\
10 \text { November } 2020\end{array}$ \\
\hline
\end{tabular}

Staphylococcus aureus is colonized in anterior nares, throat, axilla, groin, pharynx and gastrointestinal tract and damaged skin surface. Colonization provides a reservoir from which bacteria can be introduced in the body in immunocompromised. Fifty individuals newly diagnosed with Human Immunodeficiency Virus (HIV) infection and 50 non infected individuals were screened for nasal and throat carriage of Staphylococcus aureus after obtaining informed consent. Methicillin sensitive screening and other antimicrobial susceptibility testing was conducted using the disc diffusion method. The strains were characterized by phage typing. Four of $50(8 \%)$ HIV infected individuals were colonized with Staphylococcus aureus in the throat while $22(44 \%)$ were colonized in nares. None of the HIV non-infected cases had Staphylococcus aureus in the throat but 11 (22\%) was colonized with $\mathrm{S}$. aureus in the nares. The difference in the throat carriage rate between the HIV infected and HIV non infected group was not significant $(\mathrm{p}=0.117)$. Out of the four, only one HIV infected individual had exclusive throat carriage. Three out of the four strains were typable using the conventional set of phages. Only single strain was non typable. Interestingly, in the three individuals with both the throat and nasal colonization, each isolate from nasal and throat proved to have a different phage pattern. Screening limited to anterior nares may miss those individuals who may have colonization of the throat with a different strain of Staphylococcus aureus as well as exclusive colonization of throat.

\section{Introduction}

Staphylococcus aureus is the most common nosocomial pathogen, accounting for approximately $20 \%$ of all nosocomial pathogens (1). Human are natural reservoir of Staphylococcus aureus. Thirty to fifty percent of healthy adults are colonized (2). It is both a commensal organism and a pathogen. The anterior nares are the main ecological niche for Staphylococcus aureus. However, numerous other sites can be colonized, including the axilla, groin, pharynx and gastrointestinal tract and damaged skin surface. Colonization provides a reservoir from which bacteria can be introduced, when host defences are breached whether while shaving, aspiration, insertion of indwelling catheter, or surgery. Colonization clearly increases the risk of subsequent infection (3; 
4). Most of the screening programmes for Staphylococcus aureus is confined to anterior nares only. A swab specimen from throat is yet not considered to be standard due to the discomfort it adds to the patient and the cost to the health care system (5).

Some studies have found a variable frequency of Staphylococcus aureus throat carriage ranging from $4 \%$ to $64 \%$ (6). Other studies have revealed exclusive colonization of the throat which may be missed on screening anterior nares only (5). It has been said that screening throat swabs significantly increases the sensitivity of detection among carriers by $25.7 \%$ (7).

Hence, screening confined to anterior nares only, leaves behind those individuals who harbour Staphylococcus aureus in their throat. In this study we evaluated the rate of throat carriage in a selected group of population and typed the isolates obtained from throat as well as anterior nares.

\section{Materials and Methods}

\section{Bacterial strains and culture conditions}

A total of 50 newly diagnosed adult HIV infected and a equal number of HIV non infected individuals who attended the ICTC, Department of Microbiology, MAMC, New Delhi during the year 2010 were recruited in the study.

After obtaining the informed consent, a questionnaire capturing the risk factors associated with carriage was filled. Samples were taken from surface of tonsils and nasal vestibulum using a cotton swab.

The swabbed samples were directly inoculated onto the 5\% sheep blood agar, Mac Conkey agar and mannitol broth and incubated at $37^{\circ} \mathrm{C}$ for 24 h. Staphylococcus aureus isolates were identified by their colony characteristics, Gram stain appearance and a battery of standard biochemical tests (8).

\section{MRSA screening and antimicrobial susceptibility}

Using cefoxitin disc diffusion method according to CLSI guidelines, 2010 (9), all Staphylococcus aureus strains were screened for methicillin resistance. The isolates were further subjected to antimicrobial susceptibility testing to a large panel of antibiotics by the disc diffusion method employing the modified Stokes technique (10), 1993. The antibiotics discs contained: penicillin (10 IU), cephalexin (30 $\mu \mathrm{g})$, cephazolin $(30 \mu \mathrm{g})$, clindamycin $(2 \mu \mathrm{g})$, erythromycin $(15 \mu \mathrm{g})$, ofloxacin $(5 \mu \mathrm{g})$, ciprofloxacin $(5 \mu \mathrm{g})$, amikacin $(30 \mu \mathrm{g})$, gentamicin $(10 \mu \mathrm{g})$, netilmicin $(30 \mu \mathrm{g})$, tobramycin $(10 \mu \mathrm{g})$, framycetin $(100 \mu \mathrm{g})$, isepamycin $(30 \mu \mathrm{g})$, fusidic acid $(10 \mu \mathrm{g})$, chloramphenicol $(5 \mu \mathrm{g})$, rifampicin $(5 \mu \mathrm{g})$, cotrimoxazole $(1.25 / 23.75 \mu \mathrm{g})$, tetracycline $(30 \mu \mathrm{g})$, vancomycin $(30 \mu \mathrm{g})$, teicoplanin $(30 \mu \mathrm{g})$, linezolid $(30 \mu \mathrm{g})$. Standard control strains of Staphylococcus aureus used was NCTC 6571.

\section{Phage typing}

All Staphylococcus aureus isolates obtained were phage typed using standard method described earlier (11). A single colony was picked up and the phage pattern was checked using the 23 phages of the basic set at routine test dilution (RTD). Strains that were nontypable at 1 RTD were typed at 100 RTD. Non-typability was recorded when the strains were non-typable at 100 RTD.

\section{Statistical analysis}

All qualitative data was analysed using chi square test with $\mathrm{p}$ value $<0.005$ considered to be significant. 


\section{Results and Discussion}

Staphylococcus aureus was detected from either anterior nares or throat in 35 out of 100 individuals examined. Four out of $50(8 \%)$ HIV infected individuals had Staphylococcus aureus in their throat, while 22 (44\%) HIV infected individuals were grew Staphylococcus aureus in their nares. None of the HIV non infected individuals were positive for Staphylococcus aureus in their throat while $22 \%$ were positive from the nares. Only one HIV infected individual yielded Staphylococcus aureus exclusively in the throat with culture negative from the nares as shown in Table 1. The difference in the throat carriage rate between the HIV infected and HIV non infected group was not statistically significant $(\mathrm{p}=0.117)$.

When risk factors for throat carriage was studied, it was found that three out of four $(75 \%)$ individual who had throat carriage were females $(p=0.236)$. One out of four
$(25 \%)$ had history of intake of antibiotics in the past six months $(\mathrm{p}=0.464), 50 \%(2 / 4)$ had history of tuberculosis and surgery in the past $(p=0.584)$, while $25 \%$ had a history of alcohol intake and smoking $(\mathrm{p}=1.000)$ Table 2.

All the four Staphylococcus aureus isolates from the throat were methicillin sensitive. The antimicrobial susceptibility of Staphylococcus aureus isolates obtained from the throat swabs of HIV infected cases were performed against 22 antimicrobial agents. Resistance was encountered only in the case of four antimicrobial agents viz penicillin, ofloxacin, ciprofloxacin and cotrimoxazole. While all the strains were resistant to penicillin, three were resistant to cotrimoxazole $(75 \%)$ and only single isolate appeared resistant to both the fluroquinolones, ofloxacin and ciprofloxacin. Three of the four isolates of Staphylococcus aureus from throat swabs were typable. Only one strain was non typable (Figure 1).

Table.1 Staphylococcus aureus isolation rates in throat and anterior nares in HIV infected individuals

\begin{tabular}{|l|c|c|}
\hline $\begin{array}{l}\text { Results for } \\
\text { nares }\end{array}$ & Results for throat & $\begin{array}{c}\text { No (\%) of HIV } \\
\text { infected patients }\end{array}$ \\
\hline Positive & Positive & $3(6)$ \\
\hline Positive & Negative & $19(38)$ \\
\hline Negative & Positive & $1(2)$ \\
\hline Negative & Negative & $27(54)$ \\
\hline Total & & $50(100)$ \\
\hline
\end{tabular}

Table.2 Risk Factors for Throat carriage of Staphylococcus aureus

\begin{tabular}{|l|c|c|}
\hline $\begin{array}{l}\text { Risk Factors for throat carriage of } \\
\text { Staphylococcus aureus }\end{array}$ & $\begin{array}{c}\text { Percentage of } \\
\text { individuals }\end{array}$ & P value \\
\hline Females & 75 & 0.236 \\
\hline $\begin{array}{l}\text { Incidence of Antibiotic intake in past 6 } \\
\text { months }\end{array}$ & 25 & 0.465 \\
\hline History of tuberculosis & 50 & 0.584 \\
\hline History of surgery & 50 & 0.584 \\
\hline History of alcohol intake and smoking & 25 & 1.000 \\
\hline
\end{tabular}


Table.3 Comparison of phage pattern of Staphylococcus aureus isolated from throat and nares of the same HIV infected individual

\begin{tabular}{|l|c|c|}
\hline $\begin{array}{l}\text { Patient } \\
\text { No. }\end{array}$ & $\begin{array}{c}\text { Phage pattern of throat } \\
\text { isolate }\end{array}$ & $\begin{array}{c}\text { Phage pattern of nasal } \\
\text { isolate }\end{array}$ \\
\hline $\mathbf{1}$ & Group III $-42 \mathrm{E} / 47$ & Group III - 42E/47/77/83A \\
\hline $\mathbf{1 3}$ & NT & Mixed (I, III) - 52A/42E/83A \\
\hline $\mathbf{2 0}$ & Group III - 42E/47/83A & Group I - 52/52A/80 \\
\hline
\end{tabular}

Fig.1 Phage typing results of Staphylococcus aureus isolated from throat swabs

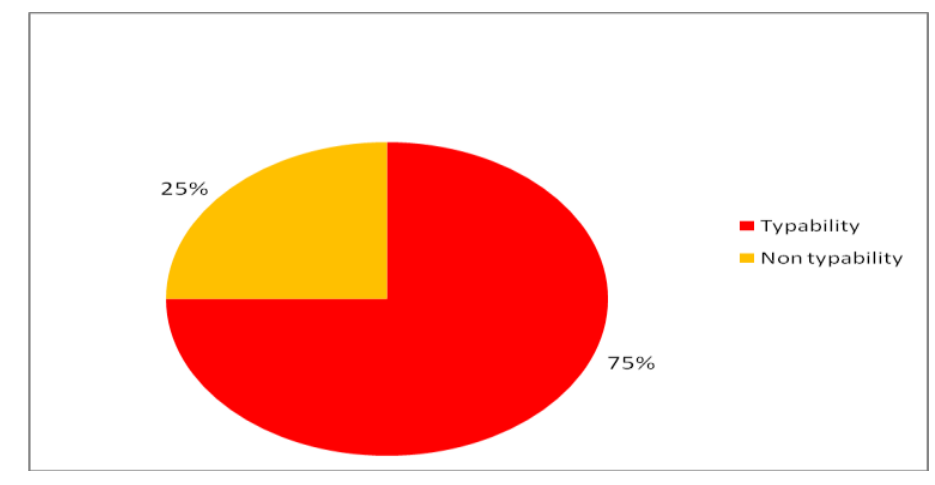

In this study, it was found that HIV infected subjects had a low rate of throat carriage $-2 \%$ of cases with exclusive throat carriage and $8 \%$ nasal and throat carriage. Even a single isolate present in the throat can cause severe infections in individuals. Several studies $(7,12,13)$ have attempted to work out the rate of throat carriage of Staphylococcus aureus either exclusively or in association with nasal carriage. None of these workers appear to have taken the HIV status of the cases studied. The present study have reported a low throat carriage rate as compared to nasal, while, one of previous study, (13) reported a much higher exclusive throat carriage of $20 \%$ than nasal carriage $8 \%$.

On comparing rate of throat carriage between HIV infected and HIV non infected individuals, it was found that HIV infected group had a higher carriage rate. Or in other words HIV infected individuals are at risk of throat carriage. This association has not been developed earlier. On studying the risk factors it was found that hospitalization in the past six months, history of surgery in the past, history of tuberculosis and alcohol intake were associated with acquisition of throat carriage.

In this study, predominantly resistance was encountered against four antimicrobial agents viz penicillin, ofloxacin, ciprofloxacin and cotrimoxazole. Not many studies in the past have done antimicrobial susceptibility from throat swabs against such a large panel of antimicrobial drugs.

On comparing the phage pattern of throat isolates from nasal isolates obtained from the same individual, it was found that the strains isolated from both the sites are not identical to each other as shown in Table 3. Hence, a different strain of Staphylococcus aureus harbouring the throat may be missed if only anterior nares are screened.

In summary, this study revealed that Staphylococcus aureus reside not only in anterior nares but throat is also an important site for its carriage. Screening only anterior nares may miss those individuals who harbour Staphylococcus aureus only in their throats. Also, an isolate in the nares may be totally different from the isolate obtained from the 
throat of the same individual. This different strain from the throat may be an MRSA while the nasal isolate may be MSSA, this type of finding may have serious implication in infection control strategy. Therefore, screening for carriage of Staphylococcus aureus should be done from both throat and nose.

\section{Aknowledgement}

Phage typing of the strains were done at the National Phage Typing Centre, Maulana Azad Medical College, New Delhi.

\section{References}

1. Styers D, Sheehan D, Hogan P, Sahm D. Laboratory based surveillance of current antimicrobial resistance patterns and trends among Staphylococcus aureus: 2005 status in United States. Ann Clin Microbiol Antimicrobiol. 2006; 5, e2. http://www.pubmedcentral.nih.gov/article render.fcgi?tool=pubmed\&pubmedid=164 69106. Accessed October 6, 2008.

2. Van Ogtrop ML. Effect of broth enrichment cultures on ability to detect carriage of Staphylococcus aureus. Antimicrob. Agents Chemother. 1995; 39: 2169.

3. Wertheim HF, Melles DC, Vos MC, et al. The role of nasal carriage in Staphylococcus aureus infections. Lancet Infect Dis. 2005; 5: 751-762.

4. Cree, R. G. A., P. Aleljung, M. Paulsson, W. Witte, W. C. Noble, A. Ljungh, and T. Wadstrom. 1994. Cell surface hydrophobicity and adherence to extracellular matrix proteins in two collections of Methicillin resistant Staphylococcus aureus. Epidemiol. Infect. 1994; 122: 307-314.
5. Mertz D, Frei R, Periat N, Zimmerli M, Battegay M, Flückiger U, Widmer AF. Exclusive Staphylococcus aureus throat carriage: at-risk populations. Arch Intern Med. 2009; 26, 169(2): 172-178.

6. Williams RE. Healthy carriage of Staphylococcus aureus: its prevalence and importance. Bacteriol Rev. 1963; 27: 5671

7. Mertz D, Frei R, Jaussi B, Tietz A, Stebler C, Fluckiger U, Widmer AF. Throat swabs are necessary to reliably detect carriers of Staphylococcus aureus. Clin Inf Dis. 2007; 45: 475-477.

8. Collee JG, Marmion BP, Fraser AG, Simmons A (eds). Mackie and McCartney Practical Microbiology $14^{\text {th }}$ edition Churchill Livingstone. New York, 1996.

9. Performance Standards for antimicrobial susceptibility testing; National Committee for Clinical Laboratory Standards Twentieth Informational Supplement. Jan 2010; 30(1): M100-S20.

10. Stokes EJ, Ridgway GL, Wren MWD. 1993. Clinical Microbiology. $7^{\text {th }}$ edn Edward Arnold A division of Hodder \& Stoughton, London.

11. Blair JE, Williams REO. Phage typing of staphylococci. Bulletin World Organisation. 1961; 771-784.

12. Uemura E, Kakinohana S, Higa N, Toma C, Nakasone N. Comparative characterization of Staphylococcus aureus isolates from throats and noses of healthy volunteers. Jpn. J. Infect. Dis. 2004; 57:21-24

13. Nilsson P, Ripa T. 2006. Staphylococcus aureus throat colonization is more frequent than colonization in the anterior nares. J Clin Microbiol. 2006; 44(9): 3334-3339.

\section{How to cite this article:}

Ruchi Kotpal, Krishna Prakash, Preena Bhalla, Richa Dewan and Ravinder Kaur. 2020. Throat Carriage of Staphylococcus aureus. Int.J.Curr.Microbiol.App.Sci. 9(11): 435-439. doi: https://doi.org/10.20546/ijcmas.2020.911.053 